- Case Report

\title{
A Case Report of Rare Adverse Events Associated with Venlafaxine Administration: Hypoglycemia and Lactic Acidosis
}

\author{
Serdar Özdemir* \\ Department of Emergency Medicine, University of Health Sciences Ümraniye Training and Research Hospital, Istanbul, Turkey
}

We report the first case of hypoglycemia and lactic acidosis caused by the therapeutic doses of venlafaxine. A 19-year-old female patient had presyncope and she was taking venlafaxine $75 \mathrm{mg}$ once a day because of major depression for a week and she had no history of any other drug use or disease. The blood gas analysis revealed hypoglycemia and lactic acidosis. Patient was treated with dextrose infusion and oral diet. Although hypoglycemia and lactic acidosis have been reported in overdose of venlafaxine in the literature, these effects were observed in therapeutic doses.

Keywords: Venlafaxine; Hypoglycemia; Acidosis; Case Report 


\section{INTRODUCTION}

Venlafaxine is a serotonin noradrenaline reuptake inhibitor commonly used for the treatment of depression. Central nervous system depression, serotonin syndrome, and cardiac conduction disorders have been associated with venlafaxine toxicity. ${ }^{1)}$ Few cases of resistant hypoglycemia and lactic acidosis due to venlafaxine overdose have been reported previously in the literature. Our knowledge is limited as the cases of hypoglycemia and lactic acidosis upon venlafaxine administration at therapeutic doses have not been reported previously within the literature. Here, we report the first case of hypoglycemia and lactic acidosis upon venlafaxine administration at therapeutic doses.

\section{CASE REPORT}

A 19-year-old woman was admitted to Emergency Medicine Department, University of Health Sciences İstanbul Ümraniye Training and Research Hospital with a presyncope. At the time of presentation, her arterial blood pressure was 130/86 mm Hg, pulse was 75 beats/min, respiratory rate was 17 breaths/min, and she was well saturated on room air. She reported a history of venlafaxine administration at a dose of $75 \mathrm{mg}$ once a day for a week because of major depression. The patient had no history of taking any other drug or disease.

Upon neurological examination, her Glasgow Coma Scale score was 14 , and she was found to be confused. The rectal touch was normal, and other physical examination findings were within the normal limits. Electrocardiography was evaluated with normal sinus rhythm. The capillary blood glucose level was assessed as $15 \mathrm{mg} / \mathrm{dL}$, and the blood glucose value was $21 \mathrm{mg} / \mathrm{dL}$ based on on the blood gas analysis. The blood gas analysis also revealed a $\mathrm{pH}$ of 7.22 , partial pressure of $\mathrm{CO}_{2}$ of $57.9 \mathrm{~mm} \mathrm{Hg}$, calculated bicarbonate of $19.3 \mathrm{mmol} / \mathrm{L}$, and a lactate level of $6.6 \mathrm{mmol} / \mathrm{L}$ (Table 1). Other initial laboratory examinations, including complete blood count, electrolytes, and liver and kidney function, were all within the normal ranges. Blood glucose was measured as $80 \mathrm{mg} / \mathrm{dL}$ after $50 \mathrm{~g}$ of dextrose infusion (10\% dextrose $500 \mathrm{~mL} / \mathrm{h})$.

Table 1. The blood gas analysis and glucose test results of patient

\begin{tabular}{lr}
\hline \multicolumn{1}{c}{ Variable } & Value \\
\hline $\begin{array}{l}\text { Blood gas analysis (at the time of admission to the hospital) } \\
\text { pH }\end{array}$ & 7.22 \\
Bicarbonate (mmol/L) & 19.30 \\
Partial pressure of $\mathrm{CO}_{2}(\mathrm{~mm} \mathrm{Hg})$ & 57.90 \\
Lactate (mmol/L) & 6.60 \\
Blood gas analysis (three hours after admission) & \\
pH & 7.37 \\
Bicarbonate (mmol/L) & 20.20 \\
Partial pressure of $\mathrm{CO}_{2}(\mathrm{~mm} \mathrm{Hg})$ & 42.40 \\
Lactate (mmol/L) & 1.60 \\
Blood glucose test result & \\
At the time of admission (mg/dL) & 21.00 \\
At 6th hour with dextrose infusion and oral diet $(\mathrm{mg} / \mathrm{dL})$ & 80.00 \\
At 9th hour with dextrose infusion (mg/dL) & 221.00 \\
\hline
\end{tabular}

Although she was on an oral diet and eating well, her blood glucose level was $80 \mathrm{mg} / \mathrm{dL}$ at 6 hours after admission. Dextrose infusion (5\% dextrose $500 \mathrm{~mL} / \mathrm{h}$ ) was continued for another 3 hours, which was stopped when the blood glucose level reached $221 \mathrm{mg} / \mathrm{dL}$.

About 3 hours after being admitted to the hospital, her blood gas analysis revealed a $\mathrm{pH}$ of 7.37, partial pressure of $\mathrm{CO}_{2}$ of $42.4 \mathrm{~mm} \mathrm{Hg}$, calculated bicarbonate of $20.2 \mathrm{mmol} / \mathrm{L}$, and a lactate level of 1.6 $\mathrm{mmol} / \mathrm{L}$ (Table 1). After medical treatment, the patient's psychiatric examination revealed that she had no suicidal ideation, took venlafaxine at the prescribed dose, and did not take any other medication. The patient was discharged with no further hypoglycemia at the 12-hour follow-up.

We asked the patient to help us to publish the case report in an international journal for discussion, including disease symptoms, diagnosis, and image related content. The patient agreed us to use his medical records and signed the informed consent form.

\section{DISCUSSION}

Venlafaxine is an antidepressant that inhibits the reuptake of serotonin and noradrenaline. In the literature, hypoglycemia associated with venlafaxine overdose has been reported in four cases. ${ }^{2-5)}$ In two of these four case reports, hypoglycemia was treated with the administration of two $50 \mu$ g subcutaneous octreotide injections. ${ }^{4,5)}$ In the other two cases, it was resolved without the administration of octreotide injections. ${ }^{2,3)}$ In our case, the patient was treated with dextrose infusion, and thus, octreotide injection was not required.

Derijks et al. ${ }^{6}$ demonstrated that hypoglycemia was associated with serotonergic antidepressants and noradrenergic antidepressants were associated with hyperglycemia. Two experimental studies indicated two possible underlying mechanisms. ${ }^{7,8)}$ Yamada et al. ${ }^{7)}$ revealed an increase in the serotonin-related insulin levels in their study, while Chi et al. $^{\text {g) }}$ demonstrated insulin-independent glucose uptake by muscle cells. In the present case, we believe that both mechanisms might be effective.

To the best of our knowledge, there are only two case reports on venlafaxine-related lactic acidosis in the literature. ${ }^{1,9)}$ In both case reports, venlafaxine overdose was used for suicide. However, bicarbonate was not used in either of the two cases. The first case was a 55 years old individual, and lactic acidosis resolved after 16 hours with hydration and activated charcoal. The second patient was a 17 years old individual, and lactic acidosis resolved after 2 hours of hydration, activated charcoal, and oxygen therapy using a face mask. In our case, it regressed after 3 hours.

Drug-induced lactic acidosis is frequently associated with the administration of metformin, isoniazid, propylene glycol, and nucleoside reverse-transcriptase inhibitors. ${ }^{9)}$ The pathogenesis of lactic acidosis is diverse. It can be caused by derangements in enzymatic processes, preferential switches in catabolic pathways, or various levels of mitochondrial dysfunction. Hroudova and Fisar ${ }^{10)}$ demonstrated that most antidepressants inhibited the activities of respiratory electron trans- 
port chain complexes, especially complexes I and IV. However, venlafaxine is associated with the inhibition of complex II. ${ }^{10)}$ Mitochondrial dysfunction caused by the inhibition of complex II may lead to an increase in glycolysis and anaerobic respiration. In the present case, the pathogenesis may be attributed to the inhibition of complex II.

We believe that venlafaxine was causal for hypoglycemia and lactic acidosis in this case because there were no other diseases that could cause these two conditions. The patient confirmed that she did not have access to any other drugs.

In conclusion, in this case, we demonstrated a unique clinical presentation of venlafaxine-induced hypoglycemia and lactic acidosis when administered at therapeutic doses. Although hypoglycemia and lactic acidosis have been reported in the cases of venlafaxine overdose in the literature, these effects were observed even at therapeutic doses in our case.

\section{CONFLICT OF INTEREST}

No potential conflict of interest relevant to this article was reported.

\section{ORCID}

Serdar Özdemir: https://orcid.org/0000-0002-6186-6110

\section{REFERENCES}

1. Eldem I, Kendirli T, Azapagası E, Ozdemir G, Yildiz C, Yilmaz MM, et al. Venlafaxine intoxication in an adolescent presenting with severe lactic acidosis. Turk J Pediatr 2016;58:200-2.

2. Meertens JH, Monteban-Kooistra WE, Ligtenberg JJ, Tulleken JE, Zijlstra JG. Severe hypoglycemia following venlafaxine intoxication: a case report. J Clin Psychopharmacol 2007;27:414-5.

3. Brvar M, Kozelj G, Masic LP. Hypoglycemia in venlafaxine overdose: a hypothesis of increased glucose uptake. Eur J Clin Pharmacol 2015;71: 261-2.

4. Francino MC, Bretaudeau Deguigne M, Badin J, Turcant A, Perrotin D. Hypoglycaemia: a little known effect of Venlafaxine overdose. Clin Toxicol (Phila) 2012;50:215-7.

5. Ling Y, Khara L, Alvarez G, McBeth PB. Persistent hypoglycemia in venlafaxine overdose. Arch Clin Med Case Rep 2019;3:94-9.

6. Derijks HJ, Meyboom RH, Heerdink ER, De Koning FH, Janknegt R, Lindquist $\mathrm{M}$, et al. The association between antidepressant use and disturbances in glucose homeostasis: evidence from spontaneous reports. Eur J Clin Pharmacol 2008;64:531-8.

7. Yamada J, Sugimoto Y, Kimura I, Takeuchi N, Horisaka K. Serotonininduced hypoglycemia and increased serum insulin levels in mice. Life Sci 1989;45:1931-6.

8. Chi TC, Ho YJ, Chen WP, Chi TL, Lee SS, Cheng JT, et al. Serotonin enhances beta-endorphin secretion to lower plasma glucose in streptozotocin-induced diabetic rats. Life Sci 2007;80:1832-8.

9. Iragavarapu C, Gupta T, Chugh SS, Aronow WS, Frishman WH. Type B lactic acidosis associated with venlafaxine overdose. Am J Ther 2016; 23:e1082-4.

10. Hroudova J, Fisar Z. Activities of respiratory chain complexes and citrate synthase influenced by pharmacologically different antidepressants and mood stabilizers. Neuro Endocrinol Lett 2010;31:336-42. 